Learning about what constitutes effective training from a pilot programme to improve music education in primary schools

Lynne Rogers, Susan Hallam, Andrea Creech, Costanza Preti Institute of Education, University of London

Contact: Professor Susan Hallam, Institute of Education, University of London, 20

Bedford Way, London, WC1H OAL

E-mail: s.hallam@ioe.ac.uk 


\title{
Learning about what constitutes effective training from a pilot programme to improve music education in primary schools
}

\begin{abstract}
The new primary strategy in England raised the profile of foundation subjects, including music, yet many primary school teachers lack skills and confidence in their ability to teach music. This research explores a year-long programme of training across 16 primary schools in England that sought to improve music education. The programme involved whole school in-service training, advisory teachers offering support within the classroom and further training for music co-ordinators. The implementation of the programme, the training received, lesson observations throughout the programme, difficulties arising and the longer term benefits were explored through questionnaires, interviews and school visits with participant teachers, and senior managers in the Local Authorities and schools. The findings indicated that the programme had been effective in improving teacher confidence, and musical understanding, and the quality of teaching. Factors contributing to the success of the programme were identified and lessons for the development and implementation of future programmes.
\end{abstract}

Key words: Primary education; training for teachers; National Curriculum 


\section{Short biographies}

Dr Lynne Rogers is Lecturer in Teacher Education Post 14 at the Institute of Education, University of London. She had extensive experience of work in schools as a music teacher and in a range of management positions prior to becoming an academic. She has undertaken extensive research in relation to behaviour in school; parenting programmes; disaffection from school including the role of alternative curricula; learning, studying and homework in adolescents; and issues relating to music education. Her publications include reports for the Department for Education and Skills and academic journal articles. She is currently chair of the Psychology of Education Section of the British Psychological Society.

Dr Susan Hallam is Professor of Education at the Institute of Education, University of London and currently Dean of the Institute's Faculty of Policy and Society. She pursued careers as both a professional musician and a music educator before becoming an academic in 1991. Her research interests include disaffection from school, ability grouping and homework and issues relating to learning in music, practising, performing, musical ability, musical understanding and the effects of music on behaviour and studying. She is the author of ten books including Instrumental Teaching: A Practical Guide to Better Teaching and Learning (1998), The Power of Music (2001) and Music Psychology in Education (2005) and over one hundred other scholarly contributions. She is past editor of Psychology of Music, Psychology of Education Review, and Learning Matters. She is past Chair of the Education Section of the British Psychological Society, treasurer of the British Educational Research Association, an auditor for the Quality Assurance Agency and an Academician of the Learned Societies for the Social Sciences. 
Dr Andrea Creech has followed careers as a professional musician, music administrator and researcher. She has held principal positions in Canadian and British orchestras, and was cofounder and Director of Clare Music Makers, a community music school in Ireland. More recently Andrea has worked on research teams for several education projects and currently is Researcher for the Dean of Faculty of Policy and Society, Institute of Education, London and facilitator/lecturer for Doctoral School Research Methods training courses. Her special research interests are musical development across the lifespan and the impact of interpersonal relationships on learning and teaching outcomes. Andrea has presented her work at international conferences and published widely.

Costanza Preti is currently a full-time ESRC and Wingate sponsored research student at the Institute of Education, University of London. She pursued a career as a professional oboist and a primary school music teacher before, in 2001, applying successfully for a grant from the 'Regione Toscana' in order to attend an MA in Music Education at the Institute of Education. Between 1996 and 2001 she was a member of a small team of resident musicians working in the paediatric oncology department of the 'Meyer' paediatric Hospital in Florence, whose work is funded by the Fondazione Livia Benini. Her research interests include the interface between music therapies, medicine and education. She is Reviews Editor of the academic journal, Psychology of Music. 


\section{Learning about what constitutes effective training from a pilot programme to improve music education in primary schools}

\section{Introduction}

Since 1994 there have been improvements in the music curriculum in primary schools in England and Wales with an increased emphasis on the class music that is offered to pupils (OFSTED, 1998). The latest annual report from the national inspection service, Office for Standards in Education, (OFSTED, 2005) stated that the achievement of pupils was good or better in around three fifths of schools, which maintained recent trends, and that the quality of teaching was good or better in nearly three quarters of schools. The new primary strategy, Excellence and Enjoyment (2003) promises to extend the provision beyond the statutory entitlement for music provided by the National Curriculum to include instrumental, vocal taster and foundation sessions for all pupils, followed by a period of free or low-cost instrumental tuition in small and larger ensemble groups. At Key Stage 2 (primary school pupils aged between 7-11 years old) a number of pilot programmes have been implemented under the Wider Opportunities initiative. This initiative seeks to provide first access for pupils at Key Stage 2 to an experience of instrumental tuition in a classroom context. Early indications are positive: there has been an increase in the percentage of the Key Stage 2 population learning a musical instrument from seven percent in 2002 to $13 \%$ in 2005 (Hallam et al., 2005).

While this appears promising, concerns remain about the many schools where the potential benefits of music education are not being realised. Some schools are held back by a lack of resources and staffing limits where music is not seen as a priority; time constraints in relation 
to duration and amount are also problematic (QCA, 2005). The development of the wholeschool music curriculum is seldom a priority: just three per cent of schools are making music the main subject focus for developing the curriculum in 2005/06 (QCA, 2005). At a national level, the Monitoring Curriculum and Assessment survey (QCA, 2005) showed music to be perceived as the most difficult foundation subject to cover at Key Stages 1 and 2. In addition, class teachers need further support if pupils are to reach the standards expected of them at the end of Key Stage 2 (OFSTED, 2005; Holden and Button, 2006).

Relevant, too, is the long-standing debate that emerged in the early 1980 s about whether primary school music in the UK is best taught by music specialists or non-specialist general class teachers (Wheway, 2006, Hennessy, 2006). Historically, primary music education had mostly been perceived as the domain of music specialists who took sole responsibility for the teaching of music to several classes meaning that many general primary school teachers did not teach music to their own classes (Mills, 1989). Those against this position, for instance, Mills, 1989; Glover and Ward, 1993; and Hennessy, 1994, have argued that this perpetuates the elitism surrounding music. Rather it is argued that general class teachers should be responsible for the music education of their class: this based on the premise that class teachers have sufficient skills to enable children to learn (see Glover and Ward, 1993; Davies, 1994; Tillman, 1998) and that general class teachers have knowledge of individual children that can be utilised in relation to their musical development and which a visiting teacher cannot hope to match (Mills, 1989).

This apparent dichotomy is not helpful. Within the current educational system there are insufficient primary music specialists (Miliband, 2004); furthermore many primary school teachers entering the teaching profession in England feel that the amount of training that they 
have received in relation to teaching music has been inadequate although the quality of that training is high (Hallam et al., 2007). Rather it is suggested that music subject leaders/coordinators should be in place in primary schools to take responsibility for the overall planning of music provision, that they should support colleagues and that the main responsibility for music in the curriculum should be with the class teacher (Glover and Ward, 1993; Hennessy, 1998). As Hennessy (2006) points out 'in many schools, if there is no champion for music on the permanent staff much of the fundamental provision and the access to enrichment are compromised.' (p. 23).

Given the new primary strategy (2003) and the increased emphasis on foundation subjects that foster an individual's talent through creativity it is pertinent to ask what may be done to help existing teachers develop their skills to improve music education in primary schools. During the late 1980s and 1990s much continued professional development work took place in primary schools to support non-specialist approaches in the teaching of music (Glover and Ward, 1993; Mills, 1989; Hennessy, 1995; 1998). Indeed, Beauchamp (1997) suggested that the lack of confidence and performance of the non-specialist primary music teacher could be rectified by in-service training. Although most forms of training were welcomed, teachers favoured support in the classroom with some element of human contact. In a recent survey, Holden and Button (2006) stated that teachers received the following types of support: published schemes for teaching music, school schemes of work, text books on music, inservice training, teacher guides, their own knowledge and ideas, help from the school music co-ordinator, television and radio programmes (these in descending order of frequency). Notable, given the suggestions from previous research, was that the least frequent form of support was that given in the classroom from a specialist musician and yet Holden and Button 
(2006) report that this was precisely the type of support that many teachers felt would be beneficial.

This research seeks to explore the implementation of a primarily vocal whole-school training programme, designed by the Voices Foundation, to improve music education in primary schools. The Voices Foundation is a national music education charity that has been working with primary schools on whole class vocal teaching for over ten years. Since its establishment in 1993, the Foundation has worked with approximately 7,000 pupils and 300 teachers and has sold a range of singing-based music courses and programmes to primary schools and teachers throughout the country. Programmes are based on a singing-based approach developed by the Hungarian music educator, Zoltan Kodaly, and linked to the National Curriculum in England by enhancing singing, listening and 'thinking' skills, as well as the understanding and knowledge of musical concepts.

The Singing Schools Programme for Primary Schools is designed to provide the training and support needed to help each teacher in the school, whatever his/her previous experience, to teach music as $\mathrm{s} /$ he teaches other areas of the curriculum. The aim is to provide a planning and teaching programme to which most teachers can readily relate and which is in line with general primary school practices; to set levels of expectation which are high, realistic and practicable; to provide the resources and advisory teacher support which facilitate and stimulate good music teaching practices; to achieve a level of musical skill which instills confidence and releases innovative teaching approaches.

The focus of this paper is to explore the implementation of a one-year training programme, the Voices Foundation Primer, in schools with no previous experience of the work of the Voices Foundation. The programme offered a whole school approach and involved all 
teaching staff including teaching assistants. It operated on three levels: whole school inservice training, the support of trained advisory teachers throughout the year and additional training for curriculum leaders to ensure long-term sustainability. All schools were sent a range of materials including song materials, CDs with recordings of the different songs and guidance about teaching music in a systematic way. At the end of the year all schools held a 'showcase' event at which all classes shared the work that they had done in the course of the year. While the focus here is on the implementation of the programme, this research was part of a larger study which considered the impact of the Voices Foundation Primer on pupils' behaviour and attitudes towards school, the quality and impact of the training including analysis of video recordings of teaching pre and post carried out by an Ofsted inspector, an experienced teacher trainer and a voice expert: see Hallam et al. (2005).

\section{Methodology}

The work in schools took place over a one-year period from September 2004 and involved 16 primary schools from three Local Authorities (LAs): one each from an inner city, urban and rural location. In each LA four to six primary schools took part. Questionnaires were developed to be administered to teachers, teaching assistants and head teachers involved with the Voices Foundation Primer. These included open questions designed to explore how the Voices Foundation Programme was implemented; the training received both prior to commencing the primer and lesson observations throughout the programme; what, if any, difficulties arose; and the longer term benefits. Visits were made to schools at the commencement of the programme and at the end of the first year of implementation. During these visits interviews were undertaken with school staff and head teachers so that the questionnaire responses might be explored in more depth. In addition, mid-term interviews 
were undertaken with 30 teachers. At the end of the school year interviews were undertaken with 11 music co-ordinators, and nine head teachers.

Interviews were undertaken also with the three LA Music Co-ordinators prior to the programme being implemented. These were followed up by mid-term interviews and post interviews with two of the three.

The findings are based on responses from staff representing 16 schools, three LA music coordinators, 12 head teachers, 11 school music co-ordinators, 70 teachers and 22 teaching assistants.

\section{Findings}

\section{Impact on teaching the National Curriculum}

Concern was raised among LA music co-ordinators that prior to the implementation of a Voices Foundation primer the National Curriculum for music was not being followed in schools:

To be honest, in some schools very little music was taking place before Voices Foundation. What has happened with this project is that every child has had the opportunity to engage with music. Previously, although music is in the National Curriculum, some teachers simply didn't do it and children could go through their education with very little musical experience. With Voices Foundation it is possible for every child to have the opportunity. It has definitely been worth it. (LA representative) 
The qualitative data indicated that in several cases teachers had not being fulfilling their obligations to the National Curriculum.

Before Voices Foundation I was not doing much National Curriculum music. I did some listening but not much teaching of musical skills. This has all changed. Through the training I now feel really confident. The kids really enjoy it. (Teacher)

Music had not been taught regularly but the training supported the teachers in changing this situation:

It does mean that we are all teaching music regularly and you know exactly what to do. So you teach it every week. It is straightforward to fit into the curriculum since you can drop in ten or fifteen minute sessions as appropriate. (Newly Qualified Teacher).

\section{Support from head teachers}

Support from head teachers was critical to the success of the programme. All participating head teachers wanted to strengthen the teaching of music across the school. For some it was the music-co-ordinator leaving or the possibility that this might happen that had pre-empted engagement with the project:

The school lacks expertise in music, our former music co-ordinator left the school recently. Few teachers have music training or can play an instrument but we all have a voice. (Head teacher) 
Head teachers were concerned that all of their staff should be able to deliver the music curriculum. This was perceived as increasing the likelihood of cross curricula links being made. There were also concerns about enhancing the curriculum in general, 'giving balance, breadth and creativity'. Others felt that it would:

Fill a gap in our curriculum - that it would inspire, energise, stimulate creativity in staff and pupils and in doing so support learning and the enjoyment of it. (Head teacher)

Some head teachers reported that the project would fit in with other current school initiatives in developing children's self-esteem and confidence. In some of the schools there was a tradition of musical activity and the programme was being engaged with to enhance this:

We firmly believe in the creative curriculum which is cohesive and allows all children to work to their strengths. Individual music tuition is being offered for violin and flute. All the children learn the recorder and drums. Our music co-ordinator is very experienced and enthusiastic. (Head teacher)

For the programme to be successful it was important that the head teacher and teachers were committed as it was demanding in terms of staff time. Teachers indicated that if the lead did not come from the Senior Management Team the programme would not be successful as it was a very challenging programme.

\section{Whole-school approach}

A whole-school approach offered positive benefits in improving the quality of music teaching. In all schools, the Voices Foundation programme was perceived as a way to 
specifically improve singing skills in teachers with the aim of improving their teaching of singing, developing a love of singing in the children, giving every child in the school an opportunity to find his/her voice, improving singing intonation, enhancing the quantity and quality of singing and enabling the school to become 'a singing school'. Important was that all members of staff were involved from the onset of the programme:

What was really important was that we had a whole school INSET at the start: it kick started everything. (Music co-ordinator)

That the teaching assistants have done the training has made a real difference. They can support the teacher in the class but they can also do singing with the pupils themselves, if, for instance, the teacher is away. (Music co-ordinator)

As part of the programme Music Co-ordinators from each school were offered an additional five-day course that offered more extensive training. This level of training was seen to be beneficial:

All music co-ordinators have come to a five-day course which has given them a lot of support and backing. There is every sense that this will be beneficial in the longer term as teachers start to explore these ideas. (LA representative)

There were further benefits in this approach since Music co-ordinators were able to develop their work in schools since all staff were participating in the programme: 
All the classes have taken this on board. It is a whole school thing. Previously when I've been on singing courses it has been difficult to come back to school and feed it through to the staff. But here everyone had the training including the teaching assistants. Everyone took to it and everyone enjoyed doing the training. (Music co-ordinator)

The success of the programme was supported by the adoption of a whole-school approach and the additional training of music co-ordinators which could feedback into the whole-school training.

\section{Training for staff: early stages of training}

The benefits of the training were evident early in the programme. All of the LA representatives suggested that the training and support for schools offered by the Voices Foundation programme was very effective. Overall evaluations were positive: some LA coordinators indicated that they wished 'every school could have it'.

The initial feedback is stunning. Everybody is thrilled with the training. There are some very good practical ideas. The teachers are really looking forward to the next one. There has been huge support and delight in the project. (LA co-ordinator)

Schools were very positive about staff enthusiasm for the training, and the way that they tried out ideas and undertook practical activities with their classes. The positive responses of the children encouraged and enthused staff to greater efforts. Teachers reported that they had learned a range of songs that they could use and had increased their understanding of music. Developing a repertoire of songs to teach was important to many teachers. They were looking for ideas, enthusiasm and inspiration and also wanted to develop expertise in relation to 
teaching in ways more appropriate to their year groups which were technically more accurate. A few teachers expected that they would be taught to teach musical notation and expressed a desire to learn more interesting songs. Particular strengths relating to the training early in the programme were the provision of resources, suggestions of specific goals to work towards, and suggestions of how to meet them. Some specific aspects also received comment:

Explaining about children's voices and the need to 'find' a voice. Emphasis on the different skills that can be learned through singing. (Teacher)

Teaching the teachers to sing the songs themselves was beneficial as it gave them the confidence to teach them, more confident than they would have been from listening to a CD. Most teachers seemed happy with the extent of the training. Overall, they felt that they had gained in confidence and were empowered to plan and implement the music curriculum more effectively structuring a course of work with progression from one step to another.

\section{The role of advisory teachers}

A particular strength of the programme, after the initial training, was the continued staff development and support provided during the year to further enhance music teaching throughout the whole school. All staff took part in ongoing INSET sessions, usually held after school, and were assisted in the classroom by advisory teachers. Generally, the ongoing training was well received.

Because of this continuous feedback it means that we are always going forward, otherwise some staff might get bored. (Music co-ordinator) 
The observations of teaching, by the advisory teachers, were felt to be helpful and the approach adopted was perceived as friendly rather than judgemental. Head teachers described the advisory teachers as 'effective' and 'inspired'. Teachers indicated that the Voices Foundation advisory teachers were passionate and enthusiastic. The feedback highlighted next steps clearly and appropriate songs were suggested for future use. The advisory teachers were reported to instil confidence.

We have been very lucky with the Voices Foundation teacher working with us and her ability to draw people in and get them involved and guide them. She has been able to write succinct critiques of what she has seen, which has helped get staff back on track and properly engaged with what it is that we want them to do, which is children learning key concepts about rhythm and pulse and being able to know the difference between short notes and long notes and thinking about lyrics, singing in different parts. (Music co-ordinator)

A prominent theme to emerge from interviews with staff was that of anxiety relating to the process of being observed. Although the advisory teachers were reported to be very good at putting staff at their ease and the observations were reported as offering support and constructive criticism, not all the responses to the observations were positive. One music coordinator described the individual feedback from the classroom sessions as 'picky at times', while some staff felt that the programme was rather rigid and did not meet the needs of specific schools. Ideas proposed by schools were felt to have been ignored.

Advisors were reported to be available for contact through telephone and e-mail and readily offered guidance between observation sessions. One LA representative was impressed with the speed with which the Voices Foundation responded when there were perceived difficulties 
relating to an advisory teacher in one school. The Voices Foundation teachers were perceived as excellent and as being key to the project. Their interactions with the teachers in the classroom and the way that they supported them, positively, even when lessons were weak, was perceived as being effective and appropriate:

It has been a very professionally run project and people who have delivered it have been very sensitive to the needs of school and staff and it has been really focused on building confidence both with children and staff, it has all been positive. It is a very brave project to run because it is trying to change the mind set of teachers. It is really changing people's attitudes and I think that it has really been positive that staff who had a negative opinion about themselves now see themselves able to deliver music. (Head teacher)

\section{Enhancing teaching skills}

The teachers reported gains in musical knowledge. Their knowledge of musical terms and understanding increased substantially:

My knowledge of terminology and my basic skills slowed my progress initially but the training observations have made this less of an issue. The voices work has helped me gain confidence, has added to my basic knowledge of terminology and general music skills. It will without doubt make my music teaching much more dynamic, knowledgeable and interesting. (Teacher) 
They reported developing specific musical skills and increasing their understanding of musical constructs, for instance, pulse, pitch and rhythm. Music co-ordinators described that as a result of the training staff were able to introduce specific musical concepts:

Staff are now using a repertoire of songs and are exploring ideas of thinking voices, pulse, rhythm, tempo, pitch and dynamics. (Music co-ordinator)

Another theme to emerge from interviews with teachers related to difficulties with learning to read music, although for some this was viewed as challenging and enjoyable.

All of the teachers had an increased repertoire of songs for teaching. This ensured that a wider range of music was available for teaching and other occasions. There were benefits to the implementation of the National Curriculum and teaching of music in general. The lesson plans provided structure and helped teachers to focus teaching and ensured coverage of key constructs, for instance, pulse, tempo. The increased repertoire enabled children to learn a number of songs and increase their understanding of musical concepts. The programme was particularly appreciated by Newly Qualified Teachers:

It is good to have appropriate songs to use with the children to teach specific musical skills such as rhythm. I have no knowledge of music and so this is very helpful. At the moment using the songs to teach the different rhythms is easy since they are straightforward. (Newly Qualified Teacher)

Teachers reported that they were now able to assess children's musical development and their progress in singing: 
I am able now to know where to start with the children and also where to start with different ability children and also I am able to assess how well they are doing with their singing. I would know where to pull them on to next. I would have progression as well. My planning has become more efficient as well. (Teacher)

As a result of increasing confidence teachers were undertaking musical activities more frequently:

The kids really enjoy it: I wish I had more time to do this. I've got a better idea of what to do in music. In terms of change to my teaching I just do more music. Music before was probably an after thought. It is also more integrated with my teaching rather than perhaps relying on class assemblies. (Teacher)

\section{The role of musical performance}

Important to the success of the training programme were the end of year celebratory performances. The Voices Foundation end of year celebrations also provided opportunities for parents to engage more with the school. In some schools a choir after-school activity had been established as a result of the success of the concert. In particular, many teachers welcomed the emphasis in the end of year celebrations on showing the process rather than the final product. In most schools the implementation of the programme had led to the introduction of regular musical performances:

We will have a public assembly at the end of the year in which each class will perform in front of the parents. This is something we have never done before. (Head teacher) 
We had a very enjoyable singing celebration. The children all took part in that and enjoyed one another's efforts and applauded one another. We haven't done that before, had an afternoon together simply singing songs. (Head teacher)

The programme had led to improvement in the quality of public performances. Some events were held outside of the school:

The status of the school was already high but the Voices Foundation programme has enhanced the music curriculum. The choir has benefited from a range of vocal activities which enhanced their performance at the local music festival. We have choir activities after school and public performances with other schools, music festivals, mass songs. (Head teacher)

\section{Obstacles to successful implementation}

\section{Issues relating to training}

Teachers reported that they were not happy with the timing of the training. In some cases the sessions were spaced too far apart during the first term and too close together in the second. Weekend training was not welcomed. Several teachers indicated that full day training required too much to be learnt at once and that half-day sessions were better. Where the training was at the end of the school day teachers reported being too tired to learn effectively. Where groups were very large many staff reported feeling inhibited from asking questions because they feared being made to look foolish. 
Several teachers suggested that training should be focused on particular Key Stages. There was concern that some teachers were learning things that they would not be able to use in the classroom:

I think that incorporating foundation stage, KS1 and KS2 has been too much. I think perhaps that some separate sessions would have been useful. (Head teacher)

Several teachers indicated that the training could have been more focused and took too long for what was learned. Teachers expressed some difficulties in remembering all the songs and actions after the training was over, although generally, teachers felt that it was useful to be taught to sing the songs and do the actions:

I have trouble remembering the songs, learning words, putting actions together and remembering the tune. Plus leading the children in all of the above. (Teacher)

\section{Visits and observations}

In one school teachers commented that the visits and observations were too frequent and that there was insufficient time for skill development between observations. Termly, rather than half termly visits were suggested. Several staff indicated that it would have been useful to observe the advisory teacher teaching before attempting to implement the strategies themselves.

\section{Fear of singing}

An issue very specific to this programme was teachers' fears about the nature of the training and having to sing aloud in front of other adults. 
People just didn't like the environment and having to sing in front of colleagues and they found it very threatening. It is a big thing to overcome. (Teacher)

Many teachers expressed concerns about the quality of their own singing, although initial fears were frequently overcame:

Started off singing very quietly and feeling silly. Overcame this by letting my guard down knowing everyone was in the same boat. (Teacher)

On the day training session I felt out of my 'comfort zone' but decided to give it $100 \%$ effort and try to enjoy day. (Teacher)

However, not all overcame the difficulties:

The training was not effective at all. I find it very intimidating, embarrassing and down-right scary. I do not like performing and singing in public. I have not overcome these fears. I feel it is impossible to implement the training as it is too stressful. (Teacher)

\section{Lack of technical knowledge}

Lack of understanding of technical terms and confusion over which songs taught specific technical elements were reported by some teachers. These difficulties were overcome through the feedback given in observation sessions or asking for guidance from the school music coordinator. Concerns were also raised regarding the level of the last training session which some teachers had found extremely difficult: 
In the last two sessions the work was too technical for people who were non-musicians and what happened is that all the confidence that had grown was knocked away. It just got a bit too technical in the end. (Head teacher)

For a few teachers, particularly those who had no prior musical training, the whole of the Voices Foundation training was too difficult:

I have had problems with the course. It's just been too hard, too over my head, this is due to my lack of expertise. Too much information and too quick. (Music co-ordinator)

A minority of staff felt very insecure about the training and others reported that the training was too inflexible and that it was not adapted to meet their needs. For those teachers with a strong musical background, the primer had little impact. Overall, the training was insufficiently differentiated to meet the needs of individual teachers.

\section{Integration with the National Curriculum}

There were mixed responses relating to the extent that the work integrated with the National Curriculum. Most teachers reported that the materials integrated well; however, in some schools teachers were planning ways to ensure continuity, progression and integration. A few schools referred to difficulties with the multi-cultural perspective and several regretted that more use was not made of percussion instruments:

Trying to fit it into the curriculum is the hardest thing, especially given SATs. I also wonder whether it could be more multi-purpose. I know that the focus is on voices but we have some 
wonderful percussion instruments and it would be good to introduce some percussion. The kids would really love it. (Teacher)

There were mixed responses, too, in relation to the wider school curriculum. A few teachers reported being better able to make links with other aspects of the curriculum, for instance, physical education, history, language and different kinds of writing. However, others indicated that the range of songs provided by the programme was too narrow to facilitate links with other project work:

I did not manage to integrate the Voices Foundation material into my topics that I was doing in the classroom. We've been doing the beach and pirates and we've learned a lot of pirate songs which the children absolutely loved. We looked through the material to see if there were songs that would support this topic and there wasn't anything so the actual range is not that good. It's a bit limited. (Teacher)

\section{Focus on the voice}

A number of concerns were raised about the stress on singing alone:

The programme is very much on singing, pitch and rhythm and on the basic skills but it doesn't tackle some of the other skills that the children need. It is difficult for non-musician members of staff to adapt the programme to something else. (Head teacher)

Indeed there was some evidence that other aspects of the National Curriculum may have been reduced as a result of the introduction of the programme: 
My concerns are about the listening and appraising side and the composing as well. We are not doing a lot of it with the children. We can use singing to cover a large part of the music curriculum whereas before we might have used instruments. (Teacher)

\section{Discussion}

Music is regarded as a difficult subject to teach in the foundation stage because of the specificity of musical expertise; and there is a clear need for primary school teachers to receive training and support in relation to teaching music in primary schools. Evidence from this research enables some consideration of the ways that training needs to be implemented if music education is to be improved in primary schools.

It is essential that training programmes utilise a whole-school approach. Here all school staff, teachers and teaching assistants were involved in the training. Music co-ordinators received additional training which enabled them to further support their colleagues in school. Important too, was real commitment from senior staff to enhance the quality of music teaching throughout the school. The demands on time for all involved were challenging and those schools wishing to seriously engage with enhancing music education need to set aside sufficient time.

Previous research had suggested that teachers have a preference for human contact in developing their skills. This study adds weight to those earlier suggestions. The use of observation from music specialists throughout the programme meant that staff were able to develop strategies, ideas and skills during the course of the year. The continued use of observation meant that staff were encouraged and enabled to continue to progress their skills and ask for advice when unsure. Also important is that the support offered matches the needs 
of individual staff and that it is timed to be most effective. The training sessions also needed to be tailored to meet need. Where teachers already had considerable musical knowledge the benefits were small. Where teachers had an insurmountable fear of singing and perceived themselves as 'tone deaf' there was little progress. Teachers also indicated that training needed to focus on the key stage that they were working in.

It is acknowledged that this one-year programme focused solely on the voice, since the Voices Foundation contends that the use of voice is more appropriate for the primary child's acquisition of the most basic music skills and concepts. However, future training programmes would benefit from avoiding a narrow focus on one element of the music curriculum, such as singing. It is important that links are made with the National Curriculum so that staff are able to plan progression and the children benefit from a wider experience.

Also important is that training programmes provide scope for children to perform music in real performance contexts.

The evidence from this research indicates that generalist teachers can develop the skills they need to teach music in the primary school. Through engaging with the programme, staff developed knowledge of musical concepts, rhythm, pulse and pitch and practical singing skills. The work of the advisory teachers was valued and their feedback was seen as supportive and helpful. Participation in the primer generally had a positive impact on teacher confidence in relation to teaching music and singing. The primer enhanced teachers knowledge of key concepts and increased the repertoire of songs available to them. Newly Qualified Teachers particularly valued the experience. The primer resulted in music being taught more frequently, and often spontaneously within the class, for short periods of time. 
Teachers reported enjoying teaching music more. Overall head teachers and music coordinators felt that the primer was well run and organised and that it had changed and improved the music teaching in the school.

\section{References}

Beauchamp, G. (1997) ‘Initial training + INSET = Confident teachers. A formula for success?' British Journal of Music Education, 14, 1, 69-85.

Davies, C. (1984) 'I can't do Music - so we just sing,' in C. Aubrey (Ed, 1994) The Role of Subject Knowledge in the Early Years of Schooling. London: Falmer Press.

Glover, J. and Ward, S. (eds) (1993) Teaching music in the primary school: A guide for primary teachers. New York: Cassell Educational.

Hallam, S., Rogers, L. and Creech, A. (2005) Survey of LEA Music Services 2005. Research Report 700 (London: Department for Education and Skills).

Hallam, S., Rogers, L., Creech, A. and Preti, C. (2005) Evaluation of a voices foundation primer in primary schools. Research Report 707 London: Department for Education and Skills. pp. 1-69 ISBN 1844786463

Hallam, S., Burnard, P., Robertson, A., Saleh, C., Davies, V., Rogers, L. and Kokatsaki, D. (2007) Trainee primary school teachers' perceptions of their effectiveness in teaching music. 
Paper presented at Research in Music Education, Annual Conference, University of Exeter, $10^{\text {th }}-14^{\text {th }}$ April.

Hennessy, S. (1994) Music 7-11: developing primary teaching skills. London: Routledge.

Hennessy, S. (1998) Coordinating Music across the Primary School. London: Falmer Press

Hennessy, S. (2006) Don't forget the teachers. Times Educational Supplement, The Teacher, March 24 $4^{\text {th }}$.

Holden, H. and Button, S. (2006) 'The teaching of music in the primary school by the nonspecialist'. British Journal of Music Education. 23, 1, 23-38.

Miliband, D. (2004) Excellence and Enrichment: New Frontiers in Music Education. Music for Life Conference. London, 3 March (2004).

Mills, J. (1989) The Generalist Primary Teacher of Music: a problem of confidence. British Journal of Music Education, 6(2), 125-138.

Ofsted (1998) Primary education: a Review of Primary Schools in England 1994-98. (London: HMSO).

Ofsted (2005) The Annual Report of Her Majesty's Chief Inspector of Schools 2004/05. (London: Ofsted). 
Qualifications and Curriculum Authority (2005) Music: 2004/5 Annual Report on Curriculum and Assessment. (London: QCA).

Tillman, J. (1988) 'Music in the Primary School and the National Curriculum', in W. Salaman and J. Mills (Ed), Challenging Assumptions: New Perspectives in the Education of Music Teachers. Exeter: Association for the Advancement of Teacher Education in Music.

Wheway, D. (2006) How is workforce reform affecting music in many primary schools? A timely snapshot. The National Association of Music Educators, 17, 4-6. 